\title{
On the Use of Calcium Fluoride as an Infrared-Transparent First Body for In Situ Temperature Measurements in Sliding Contact
}

\author{
H. Kasem · P. Dufrénoy $\cdot$ Y. Desplanques • \\ M. Siroux • B. Desmet
}

Received: 27 October 2010/Accepted: 20 December 2010/Published online: 7 January 2011

(C) Springer Science+Business Media, LLC 2011

\begin{abstract}
This article presents an investigation of the temperature changes in dry sliding contact for braking applications. An original metrology method was developed using a special pad with a calcium fluoride 'window' in its centre. As calcium fluoride is transparent to infrared radiation (up to $92 \%$ in $1-5 \mu \mathrm{m}$ spectra), it allows access to the disc surface during friction for estimating its temperature using a twocolour pyrometer. Using this set-up, the surface temperature of the disc was successfully determined during friction. In addition, the temperature in the contact area was compared to that measured immediately outside the contact area; the difference between them proved to be very minimal $(<5 \%)$. The effect of introducing a calcium fluoride 'window' on friction was also studied, and the results show that its use does not affect the friction coefficient. Finally, the wear mechanisms of the calcium fluoride were studied through the characterisation of the worn surfaces using several techniques.
\end{abstract}

Keywords Friction - In situ temperature measurement . Calcium fluoride $\cdot$ Two-colour pyrometry

\section{Introduction}

During braking, the temperature levels and distributions generated by friction at the contact interface are complex

H. Kasem - M. Siroux · B. Desmet

TEMPO, UVHC, Univ. Lille Nord de France, 59313

Valenciennes, France

H. Kasem $(\varangle) \cdot$ P. Dufrénoy · Y. Desplanques

Laboratoire de Mécanique de Lille (LML UMR CNRS 8107),

USTL, Univ. Lille Nord de France, 59655 Villeneuve d'Ascq

Cedex, France

e-mail: haytam.kasem@polytech-lille.fr phenomena that directly influence braking performance. Indeed, temperature rises can lead to surface damage such as oxidation [1,2], the formation of hot spots [3-5] and the propagation of cracks arising from cyclic thermomechanical fatigue problems $[6,7]$. Furthermore, when coupled with severe tribological loads, a rise in temperature may increase the likelihood of tribological transformations of surface 'TTS' [8] and influence third-body behaviour at the contact interface [9]. Thus, given all of the above, it is clear that the surface temperature during braking plays an important role in brake disc surface failure. The knowledge of the true surface temperature during braking is, therefore, a vital element that must be taken into account in the design of brake components.

Despite the many investigations reported in the literature over the past few decades [10-12], the measurement of the true temperature attained in sliding contact during friction remains particularly tricky and unclear. On the one hand, the direct contact method that uses thermocouples located a few millimetres beneath the rubbing surface provides information about the subsurface temperature [13-15], but not that of the surface itself. On the other hand, the noncontact method-also known as the radiometric methodcan only provide information about the surface temperature immediately outside the contact area because of the inaccessibility of the contact surface during friction $[4,16,17]$. In addition, variations in surface emissivity over time and space make it difficult to accurately determine the surface temperature [18].

In the light of the above, the present work aims to develop an original in situ thermal metrology method specially for sliding contact, particularly in braking applications. This metrology method will allow us to determine the true temperature and emissivity variations on the disc surface during braking by means of a special fibre-optic 
two-colour pyrometer [18-20]. A small 'window' consisting of a calcium fluoride disc is inserted into the central part of a pad to enable in situ thermal measurements within the sliding contact area.

In this article, the materials investigated and the design of an OMC pad containing a calcium fluoride disc are first presented. The two-colour pyrometery technique used for measuring surface temperatures (while taking into account emissivity variation in this particular case through in situ measurements) and the necessary precautions are then developed. Finally, the results obtained for in situ thermal measurements as well as the characterisation of worn surfaces are presented and discussed.

\section{Experimental}

\subsection{Materials Investigated}

The materials investigated were commercial friction materials designed for railway braking applications in intra-urban transport. The friction pair was composed of a disc made of XC38 steel and a special pad made of an organic matrix composite (OMC) with a small calcium fluoride disc incorporated into its centre. The disc was $160 \mathrm{~mm}$ in diameter and $11 \mathrm{~mm}$ thick, while the pad was $37 \mathrm{~mm}$ in diameter and $15 \mathrm{~mm}$ thick. These disc and pad diameters were chosen for a geometric factor of 18 , which is close to that in a full-scale railway (TGV) disc brake [21]. The pad had a hole cut through its centre to accommodate the calcium fluoride disc $(\varnothing=8 \mathrm{~mm}$ and $H=5 \mathrm{~mm}$ ), which was adhered to the pad by means of a thermal adhesive applied around its circumference (Fig. 1). During braking experiments, thermal measurements on the disc surface were performed through this calcium fluoride

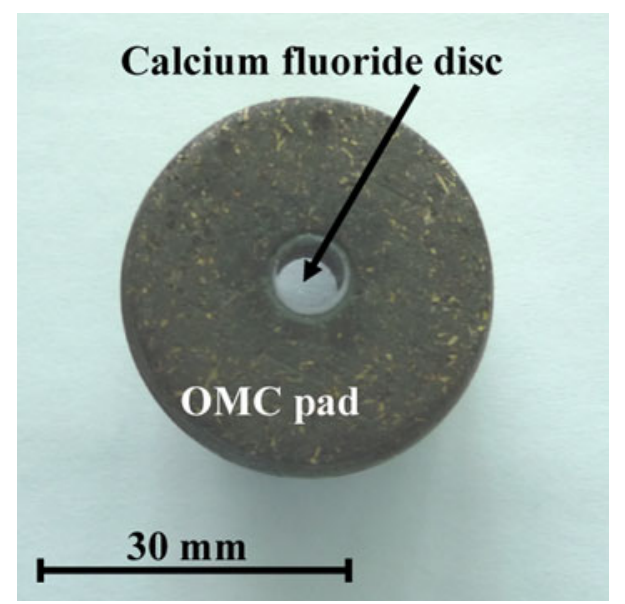

Fig. 1 Calcium fluoride disc incorporated (adhered) into the centre of the OMC pad

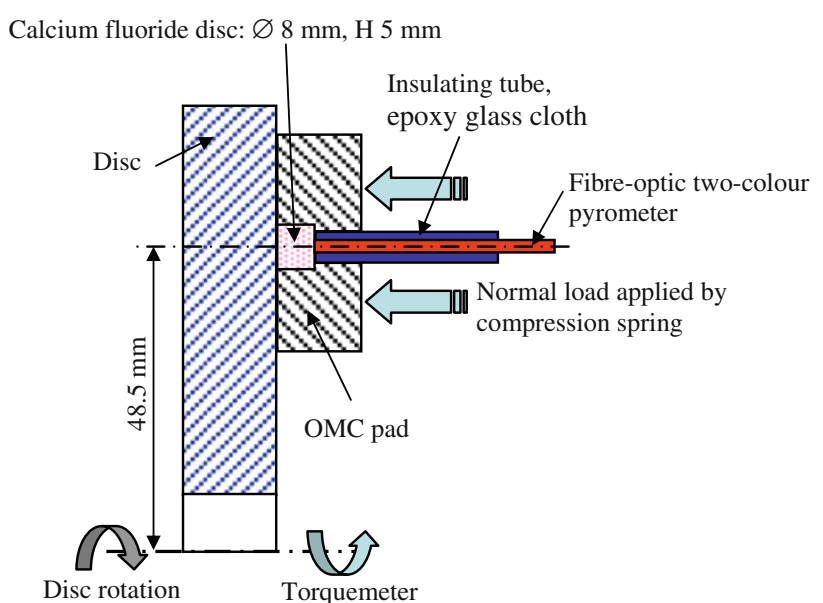

Fig. 2 Configuration of the friction pair (pad and disc) with a calcium fluoride disc incorporated into the pad

'window' using a fibre-optic two-colour pyrometer (Fig. 2). The calcium fluoride, which was polished along with the pad surface, also prevented the accumulation of wear debris (third body) in the hole of the pad containing the calcium fluoride, thereby making the disc surface accessible (unconcealed) for thermal measurements during friction.

Calcium fluoride was chosen for two main reasons:

- its high transparency in infrared spectra $(92 \%$ for $1-5 \mu \mathrm{m})$;

- its suitable capacity for wear, which ensured that the whole pad surface (OMC and calcium fluoride) would wear down at the same average rate. This prevented heterogeneous load distributions, which could have occurred if the calcium fluoride wore down more slowly than the OMC (see illustration in Fig. 3).

The relatively small diameter of the calcium fluoride disc $(8 \mathrm{~mm})$ was chosen to minimise its influence on the nature of the $\mathrm{pad} / \mathrm{disc}$ contact, i.e. OMC/XC38 steel. Indeed, the calcium fluoride occupied less than $5 \%$ of the total pad area. Also, its thickness of $5 \mathrm{~mm}$ was chosen as a compromise between the capacity to absorb infrared radiation and mechanical strength.

\subsection{Tribometer}

Braking tests were performed on a laboratory pin-on-disc tribometer with a horizontal axis. Figure 4 presents a general schematic drawing of the device. This tribometer, which was developed at the Laboratoire de Mécanique et d'Energétique in Valenciennes, is capable of reproducing holding (120 s) and endurance (20 min) braking tests at a reduced scale [22]. A compression spring applied a normal load of up to $860 \mathrm{~N}$ on the pad, thereby allowing a 
Fig. 3 a Homogeneous load distribution thanks to equal wear rates of (OMC) pad and calcium fluoride;

b heterogeneous load distribution caused by lower wear rate of calcium fluoride compared to that of the OMC pad
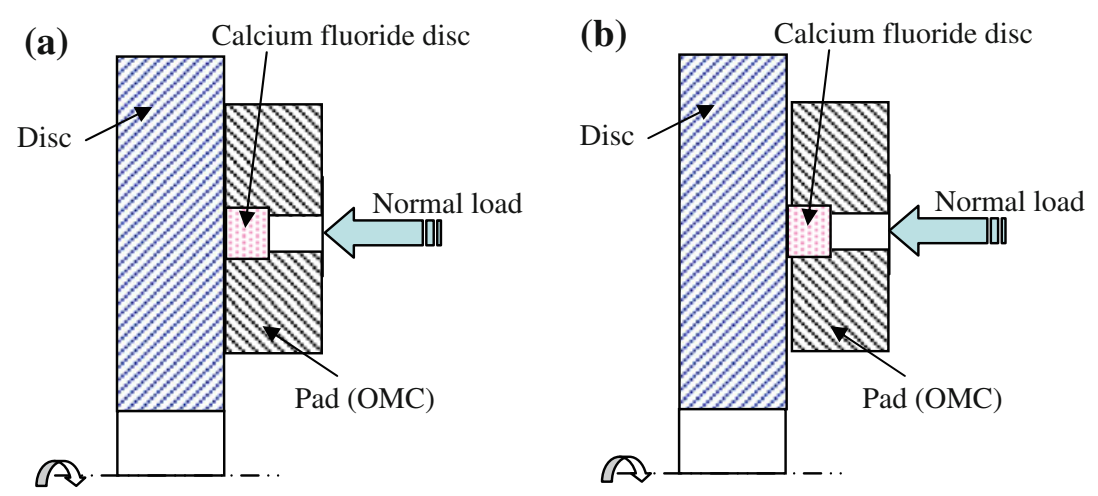

Fig. 4 Braking tribometer with horizontal axis in pin-on-disc configuration for braking simulations at reduced scale

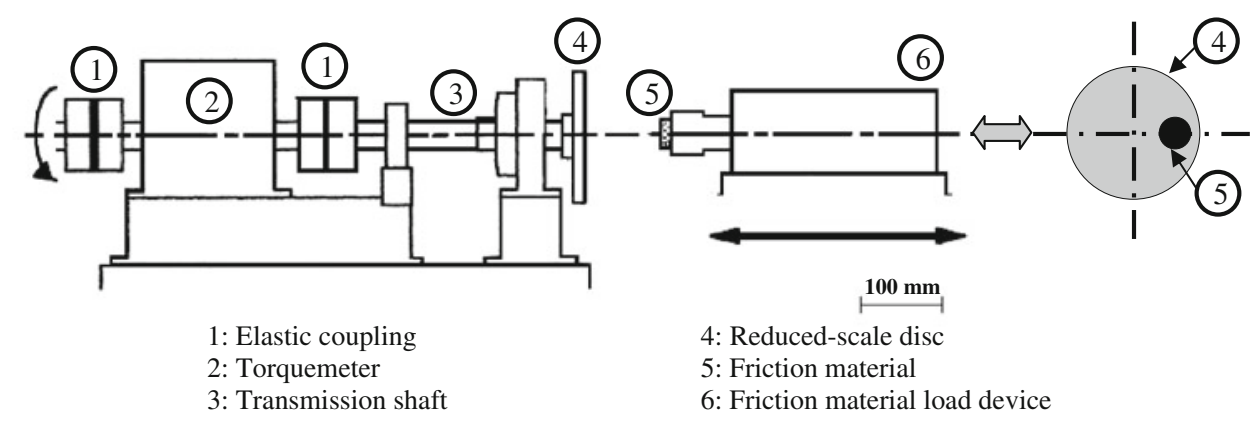

maximum apparent pressure of $0.8 \mathrm{MPa}$. The apparent contact pressure $P$ was determined from Eq. 1:

$P=K * L / S_{\mathrm{p}}$

$K$ being the spring rate $(26200 \mathrm{~N} / \mathrm{m}), L$ the compression of the spring and $S_{\mathrm{p}}$ the apparent friction area of the pad.

An electric motor drove the disc at a rotational speed of up to $372 \mathrm{rpm}$, corresponding to a maximum sliding velocity of $2.33 \mathrm{~ms}^{-1}$ for a disc diameter of $160 \mathrm{~mm}$. A torquemeter located directly on the disc shaft also allowed us to monitor the friction couple, $C \mu$, generated by friction drag.

\subsection{Temperature Measurements during Braking Experiments}

The temperature of the disc surface during friction was measured by:

- a monochromatic pyrometer (Impac) positioned so as to focus on the mid-radius of the disc track at a spot immediately outside the contact area;

- a fibre-optic two-colour pyrometer developed for braking applications (temperature range $220-1000{ }^{\circ} \mathrm{C}$ with response time of $8 \mu \mathrm{s})$. The optical fibre was held in place in the centre of the pad (mid-radius of $48.5 \mathrm{~mm}$ ) by means of an insulating tube made of epoxy glass cloth, which also served to protect the optical fibre from the heat generated by friction (see Fig. 2). The distance between the optical fibre and the rubbing surface of the disc was $5 \mathrm{~mm}$ (i.e. the thickness of the calcium fluoride disc), which led to a spot diameter of $2.4 \mathrm{~mm}$ [19]. The angular distance between the monochromatic and the fibre-optic two-colour pyrometers was $35^{\circ}$ (see Fig. 5).

The fibre-optic two-colour pyrometer was composed of two HgCdTe detectors equipped with two bandwidth filters (central wavelengths $\lambda_{1}=2.55 \mu \mathrm{m}$ and $\lambda_{2}=3.9 \mu \mathrm{m}$ ), a fluoride glass optical fibre and a data conditioning and acquisition device. The two-colour pyrometer measured the energy radiated by the brake disc for the two bandwidths, thereby allowing us to determine the true temperature and surface emissivity [18, 19, 23].

Infrared absorption by the calcium fluoride disc was systematically taken into consideration by placing the calcium fluoride disc between the fibre-optic two-colour pyrometer and a black-body furnace during calibration. The variation in infrared-transparency of the calcium fluoride arising from friction (surface state modification) was evaluated and taken into account by repeat calibrations performed before and after each friction experiment (see illustration in Fig. 6). The calibration procedure consisted in determining the amplification constants, $A_{\lambda_{1}}$ and $A_{\lambda_{2}}[19$, 23]. Such a systematic calibration revealed a decrease in the transparency of calcium fluoride in the infrared spectra considered during the first 10 min of friction; indeed, both detectors recorded a decrease of up to $85-90 \%$ in the transparency of the polished calcium fluoride. For longer friction durations, the transparency was found to become stable around this value (see Fig. 7). The stabilization of 
Fig. 5 Location of two-colour and monochromatic pyrometers

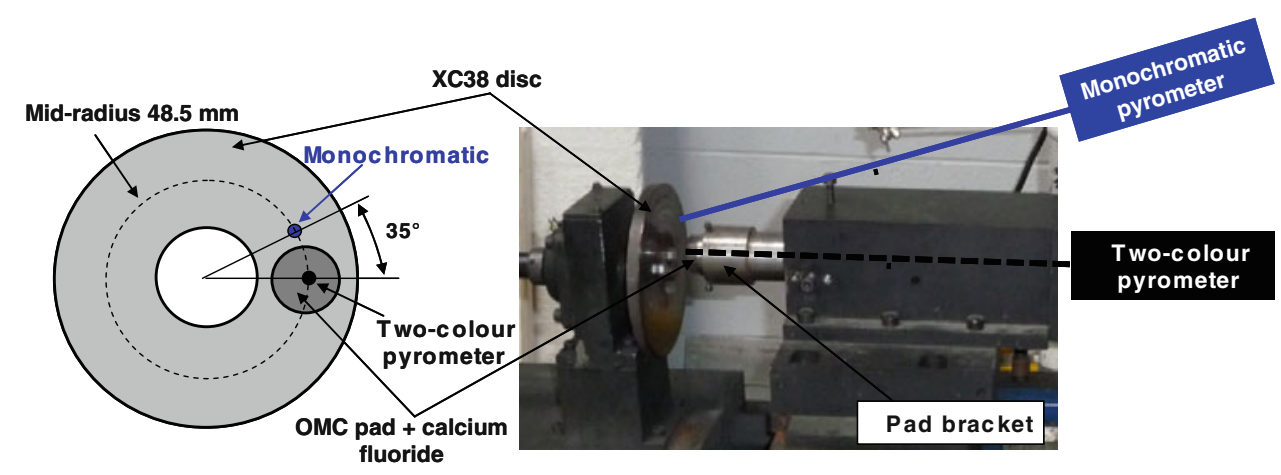

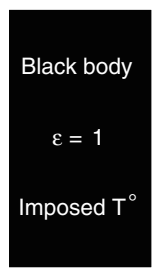

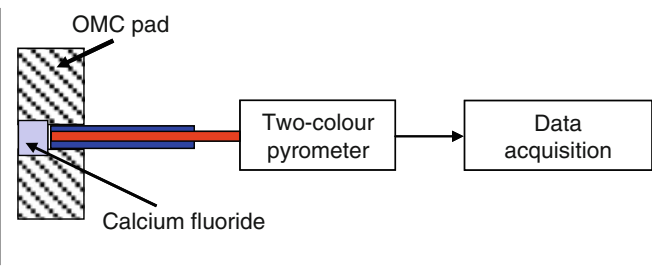

Fig. 6 Schematic illustration of the systematic calibration (before and after each test) using a black body to take into account the transparency of the calcium fluoride

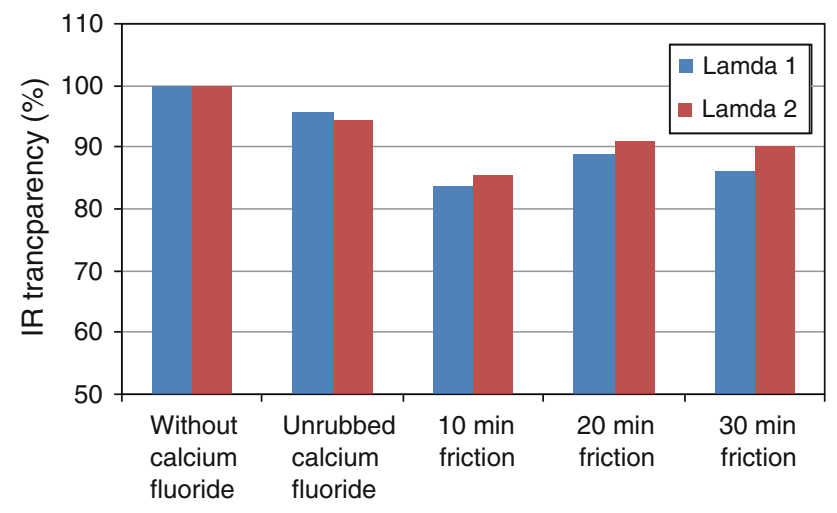

Fig. 7 IR-transparency of the calcium fluoride for both detectors, $\lambda_{1}$ and $\lambda_{2}$, as a function of friction time

the transparency may be explained by the attainment of a stationary damage state of the rubbing surface of calcium fluoride after $10 \mathrm{~min}$ of friction. This will be discussed in greater detail and complemented by worn surface characterisations in Sect. 3.2.

\subsection{Experimental Procedure}

All friction experiments were preceded by a preliminary rubbing of the mating surfaces (pad and disc) to help ensure good contact between the latter and raise the disc surface temperature up to the functioning temperature of the two $\mathrm{HgCdTe}$ detectors used, i.e. at least $220{ }^{\circ} \mathrm{C}$. The experimental operating parameters were:
- an initial surface temperature of at least $220^{\circ} \mathrm{C}$;

- a rotational speed of $372 \mathrm{rpm}$, corresponding to a linear speed of $1.9 \mathrm{~ms}^{-1}$ at the pad centre;

- a normal load of $540 \mathrm{~N}$, corresponding to an apparent contact pressure of $0.48 \mathrm{MPa}$.

All experiments were performed in air.

The output signals from the two detectors of the twocolour pyrometer, the monochromatic pyrometer and the torquemeter were recorded by means of a data acquisition system (DM3000 GRAPHTEC), in 16-s sequences at a frequency of $1 \mathrm{kHz}$. This high-acquisition frequency allowed us to capture fast temperature variations of up to $1 \mathrm{~ms}$ in the contact area.

\section{Results and Discussion}

\subsection{Thermal Measurements}

Figure 8 presents the variation of the true disc surface temperature $\left(T^{\circ}\right.$-bi) measured in the contact area through the calcium fluoride 'window', and the monochromatic temperature measured immediately outside the contact area, i.e. at a spot on the mid-radius of the disc that is just leaving the contact area $\left(T^{\circ}\right.$-mono), obtained by the

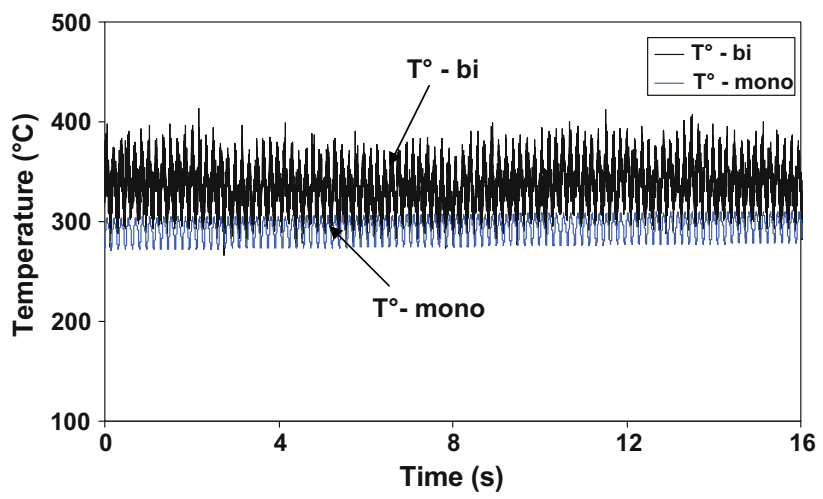

Fig. 8 Variation of the true temperature in the contact area $\left(T^{\circ}\right.$-bi) calculated by taking into account the true emissivity and the monochromatic temperature measured immediately outside the contact area $\left(T^{\circ}\right.$-mono), assuming black-body behaviour $(\varepsilon=1)$ 
monochromatic pyrometer, assuming black-body behaviour $(\varepsilon=1)$. It can be seen that the average true surface temperature in the contact area $\left(T^{\circ}\right.$-bi) is $340{ }^{\circ} \mathrm{C}$, with fluctuations of relatively large amplitude $\left(\Delta T^{\circ}\right.$ bi $\sim 100^{\circ} \mathrm{C}$ ) that reflect circumferential thermal gradients. The average monochromatic temperature $\left(T^{\circ}\right.$-mono) is lower at $291{ }^{\circ} \mathrm{C}$, and the amplitude of its fluctuations are also smaller $\left(\Delta T^{\circ}\right.$-mono $\left.\sim 30^{\circ} \mathrm{C}\right)$.

Let it be reminded here that the monochromatic temperature $\left(T^{\circ}\right.$-mono) is measured immediately outside the contact area while assuming black-body behaviour for the disc surface $(\varepsilon=1)$. In order to compare the temperatures measured inside and immediately outside the contact area, the monochromatic radiance temperature, $T^{\circ}$-mono, was corrected using the surface emissivity given by the twocolour pyrometer measurement. In addition, the difference in location of the two infrared measurements-one at the centre of the contact area where the two-colour pyrometer was positioned and the other immediately outside the contact area at $35^{\circ}$ from the contact centre on the same radius-was taken into account by means of a time shift, in which the emissivity-corrected $T^{\circ}$-mono was brought forward by $8 \mathrm{~ms}$, corresponding to the $35^{\circ}$ shift in the linear sliding speed of $1.9 \mathrm{~ms}^{-1}$.

Figure 9 shows the emissivity-corrected and time-shifted temperature $\left(T^{\circ}\right.$-mono-corr) measured immediately outside the contact area and the true surface temperature ( $T^{\circ}$-bi) obtained by the two-colour pyrometer in the contact area. It can clearly be seen that the corrected temperature just outside the contact area ( $T^{\circ}$-mono-corr) is very slightly lower compared to that measured in the contact area by the two-colour pyrometer $\left(T^{\circ}\right.$-bi), the difference between them being less than $5 \%$. These preliminary results seem to prove that in some braking applications, radiometric thermal measurements performed immediately outside the contact area that take into account emissivity variations could be sufficiently representative for the study of tribological behaviour from a thermal point of view.

In addition, it can also be observed that the fluctuation amplitude of the corrected temperature in Fig. 9 $\left(\Delta T^{\circ}\right.$-mono $\left.\sim 100{ }^{\circ} \mathrm{C}\right)$ is much greater than that of the uncorrected one in Fig. $8\left(\Delta T^{\circ}\right.$-mono $\left.\sim 30{ }^{\circ} \mathrm{C}\right)$. This clearly shows that in radiometric temperature measurements, the consideration of surface emissivity, which varies in space and time, leads to a better estimation of the thermal gradients that reflect the temperature distribution in the contact area. Indeed, the use of a monochromatic pyrometer or infrared camera alone (assuming black-body behaviour, $\varepsilon=1$ ) systematically leads to an underestimation of both the true surface temperature and the intensity of thermal gradients.

Figure 10 presents the expanded signals of the surface temperature measured by the two-colour pyrometer, $T^{\circ}$-bi,

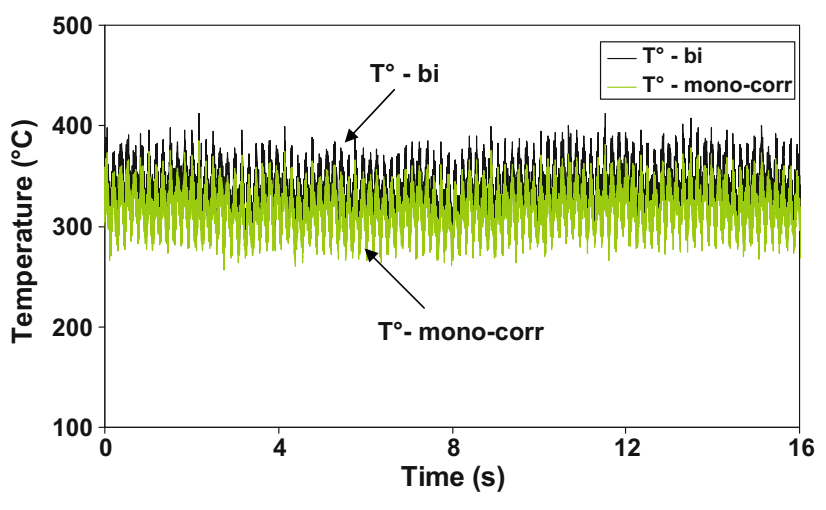

Fig. 9 Variation of the true temperature in the contact area $\left(T^{\circ}\right.$-bi) and the corrected monochromatic temperature measured immediately outside the contact area $\left(T^{\circ}\right.$-mono-corr), with true surface emissivity being taken into consideration

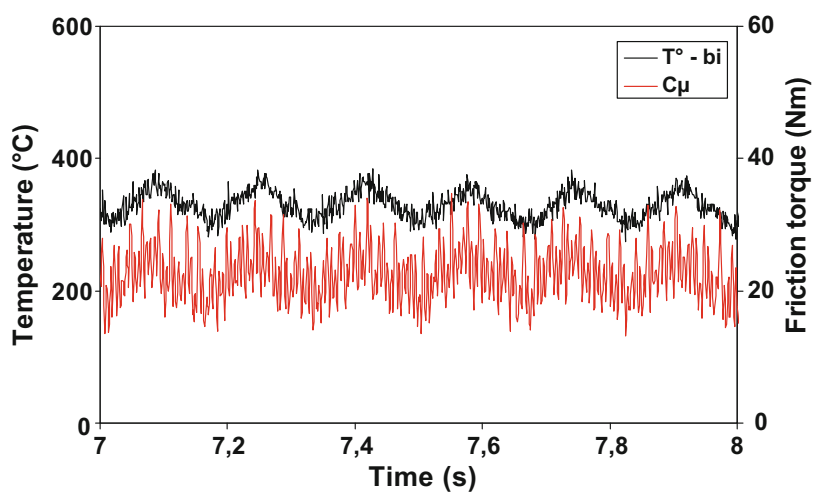

Fig. 10 Expanded signal of the true temperature in the contact area $\left(T^{\circ}\right.$-bi) calculated by taking into account the true emissivity and the friction torque measured by the torquemeter

and the friction torque, $\mathrm{C} \mu$, measured by the torquemeter located on the disc shaft. It can clearly be seen that the two signals vary in phase with each other, i.e. warm areas correlate with high-frictional drag. In addition, let us recall that the disc rotational speed was $372 \mathrm{rpm}$, which corresponds to a frequency of $6.2 \mathrm{~Hz}$ that can easily be identified on both signals as they go through six cycles per second. This result can be explained by an out-of-plane deformation of the disc, which induces a local increase in the normal load, leading to an increase in frictional drag (assuming a constant friction coefficient) and consequently surface temperature as a result of the significant amount of energy dissipated in this area.

\subsection{Influence of Calcium Fluoride on the Friction Coefficient}

In order to evaluate the influence of the calcium fluoride disc incorporated within the OMC pad on the friction coefficient, additional friction tests were carried out to 
Fig. 11 Friction coefficient profiles: $\mathbf{a}$ and $\mathbf{c}$ without calcium fluoride; $\mathbf{b}$ and $\mathbf{d}$ with calcium fluoride (a)

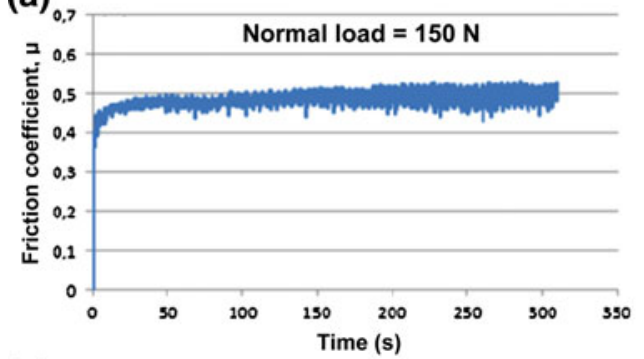

(c)

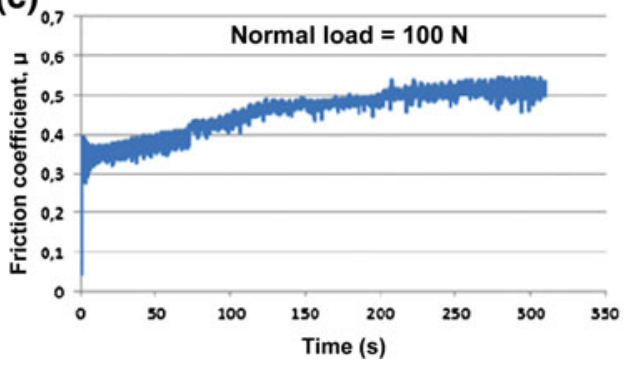

(b),

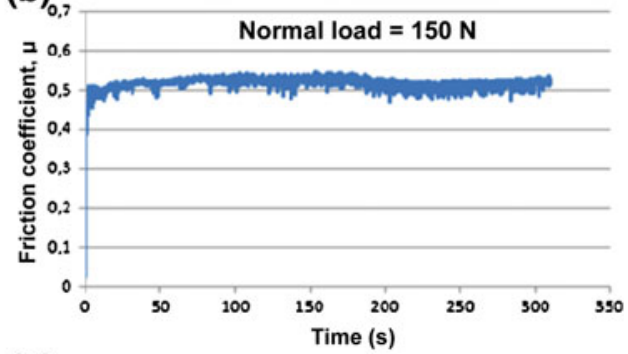

(d)

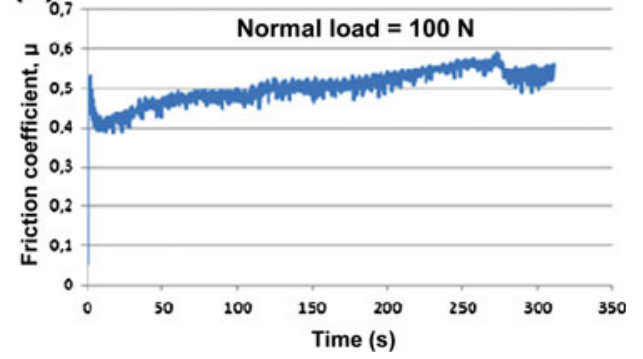

study the variation of the friction coefficient for pads with and without calcium fluoride.

The results presented in the previous section were obtained for an OMC pad of $38 \mathrm{~mm}$ in diameter, in which calcium fluoride accounted for only $4.7 \%$ of the total friction area. To study the influence of the inserted calcium fluoride disc, we deliberately increased the surface ratio of the calcium fluoride over the total pad surface in order to amplify any effect of the calcium fluoride on the friction coefficient. Thus, two pads, 'A' and 'B' $(\varnothing=20 \mathrm{~mm})$, were prepared: pad A was entirely made of OMC, while pad B was made of OMC containing a small calcium fluoride 'window' $(\varnothing=8 \mathrm{~mm})$ in its centre. The area occupied by calcium fluoride, therefore, accounted for about $16 \%$ of the total friction area of pad B, i.e. about four times greater than in the tests presented in Sect. 3.1. These pads were rubbed against a steel XC38 disc $\left(\varnothing_{\text {out }}=100 \mathrm{~mm}\right.$ and $\varnothing_{\text {inn }}=40 \mathrm{~mm}$ ). The friction tests were conducted on a vertical-axis pin-on-disc tribometer capable of accurate friction coefficient measurements. The operating friction parameters were:

- a disc rotational speed of $300 \mathrm{rpm}$;

- normal forces of 100 and $150 \mathrm{~N}$, corresponding to mean contact pressures of 0.3 and $0.45 \mathrm{MPa}$, respectively;

- a test duration of $300 \mathrm{~s}$.

For each test, 10 min of preliminary mechanical grinding were performed to ensure good contact between the mating surfaces.
The results show that the friction coefficient profiles obtained with and without calcium fluoride are very similar for all applied normal loads (Fig. 11). This clearly shows that the introduction of a small calcium fluoride disc does not affect the friction coefficient and consequently validates its use as an infrared-transparent 'window' within a first body for in situ temperature measurements and/or optical observations by fast optical cameras.

\subsection{Characterisation of Worn Surfaces}

After friction, worn surfaces were characterised by different techniques to study wear mechanisms.

\subsubsection{D Optical Laser Profilometer}

This technique allows us to evaluate the worn surface roughness and plot 3D representations of the morphology of rubbed surfaces. Figure 12 shows a 3D representation of the worn surfaces of the calcium fluoride disc and the OMC pad. It reveals that the rubbing surfaces of the calcium fluoride and the OMC lie approximately on the same plane. This indicates that the two materials experienced a similar wear rate (similar thickness loss), which implies good pressure distribution in the contact area during friction, and, therefore, justifies the choice of calcium fluoride as a transparent first-body material (see Fig. 3). Although the surfaces of the calcium fluoride and OMC lie roughly on the same plane, this is not the case for the thermal adhesive (Araldite) that was used to fix 
Fig. 12 3D profilometer observation of the worn pad surface

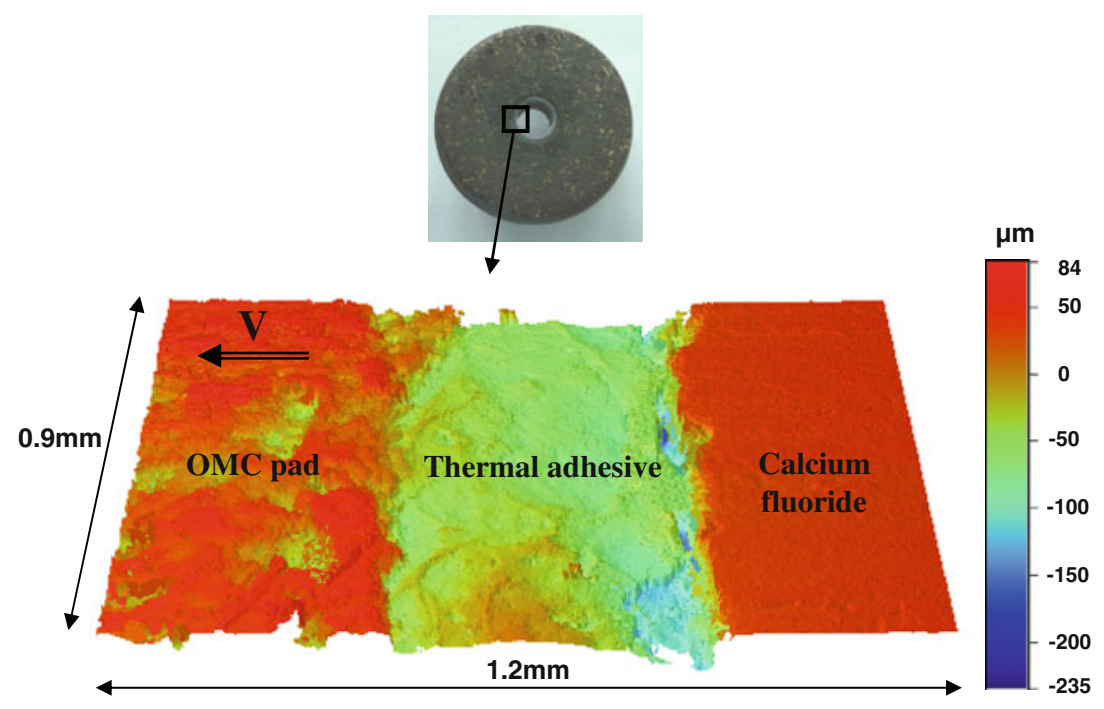

the calcium fluoride disc within the OMC pad and effectively constituted the interface between the two. Indeed, the wear resistance of the adhesive is lower than that of the calcium fluoride and OMC as seen from its worn surface that lies about $100 \mu \mathrm{m}$ below the main friction plane. However, this difference between adhesive and pad wear rates does not affect our study as the calcium fluoride disc remained well embedded in the OMC pad throughout all the friction experiments.

Figures 13 and 14 present the worn surface states of the calcium fluoride and OMC pad, respectively. The calcium fluoride has an overall 'polished' aspect, albeit with a third body trapped locally in certain areas that are shown in red in Fig. 13a. This local third body does not seem to cause any significant reduction in the IR transmissibility of the calcium fluoride (see Fig. 7) and, therefore, allows proper thermal radiometric measurements to be performed through it. The surface roughness of calcium fluoride seems to attain a stationary state with $R_{\mathrm{a}}$ values of 0.37 and $1.3 \mu \mathrm{m}$ parallel and perpendicular to the sliding direction, respectively (see Fig. 13b, c). These surface roughness values are significantly lower than those of the OMC pad, which has $R_{\mathrm{a}}$ values of 3.17 and $12.36 \mu \mathrm{m}$ (see Fig. 14b, c). An analysis of the morphologies of the two materials indicates that the calcium fluoride experiences a 'mild' wear mechanism with detachment of small-sized particles, leading to a worn surface with a 'polished' aspect that contrasts with that of the OMC pad.

\subsubsection{SEM Analysis}

To identify more precisely the wear mechanisms involved during friction, SEM observations (Hitachi SEM) were performed on the worn surfaces. Figure $15 \mathrm{a}$ and $\mathrm{b}$ shows low-magnification SEM observations of the worn surfaces of the calcium fluoride disc and the OMC pad. These observations confirm the 'polished' aspect of the calcium fluoride that contrasts with that of the OMC pad; there is, however, evidence of a local third body trapped in certain areas of the calcium fluoride (Fig. 15a). A high-magnification observation presented in Fig. 16 reveals the presence of 'mild' scratches resulting from abrasion mechanisms occurring in the contact area during friction. In addition, this observation reveals the development of microcracks on the surface of the calcium fluoride. These characterisations show that the main degradation/wear mechanisms of the calcium fluoride take the form of 'mild' abrasion and microcracks leading to the detachment of small-sized particles. The small size of these detached particles prevents any significant deterioration of the rubbed surface during friction and helps maintain a stationary state that is sufficiently 'polished' for radiometric measurements to be carried out.

While calcium fluoride is generally used as an additive in lubricants [24], these results appear to prove that contrary to preconceived notions, calcium fluoride may be used effectively as a first body in some tribological applications, especially in in situ thermal measurements and/or contact surface observations by an IR camera.

\section{Conclusion}

An original thermal metrology method for in situ temperature measurements in rubbing sliding contact in braking applications was developed and tested. This method consisted in measuring the disc surface temperature in the contact area, by means of a two-colour pyrometer, through a small calcium fluoride piece incorporated within the friction pad. 

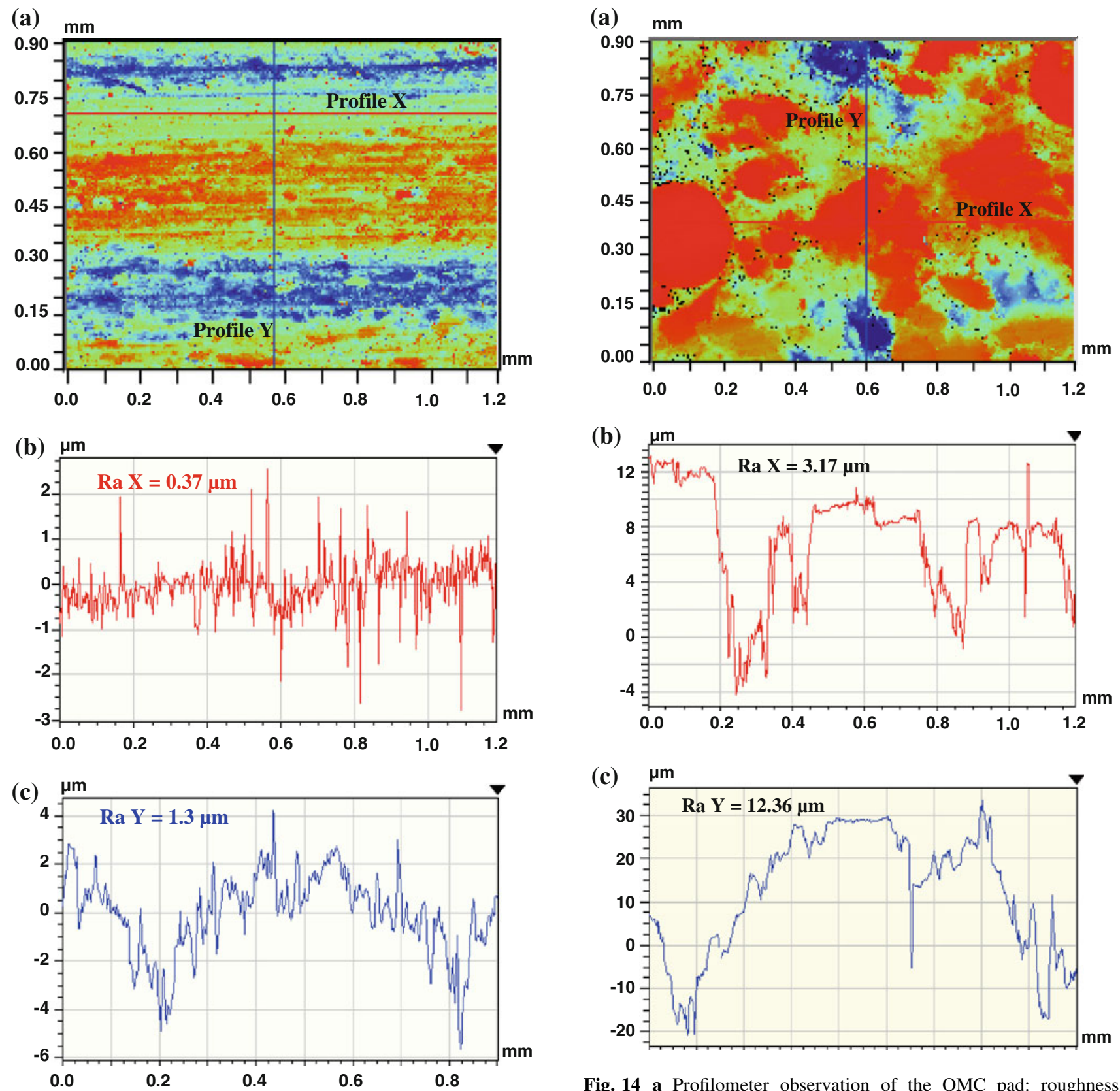

Fig. 14 a Profilometer observation of the OMC pad: roughness, b parallel and $\mathbf{c}$ perpendicular to the sliding direction

Fig. 13 a Profilometer observation of the calcium fluoride: roughness, $\mathbf{b}$ parallel and $\mathbf{c}$ perpendicular to the sliding direction

The true temperature in the contact area was successfully determined with consideration of the variation in surface emissivity and the IR absorption of the calcium fluoride. The temperature in the contact area was compared with that measured immediately outside the contact area: the first results show that the difference between the two is relatively minimal (less than 5\%). These findings suggest that in some applications, the temperature measured just outside the contact area may be sufficient for the study of tribological performance. In addition, the results show that

the consideration of the variation in surface emissivity during braking leads to a better estimation of the true temperature and the intensity of thermal gradients.

Although calcium fluoride degrades and loses its polished (mirror) aspect after initial braking, it seems to undergo a 'polishing process' during friction and indeed attains a stationary mild surface damage state, which is considered largely sufficient for the present application. The main degradation wear mechanisms of the calcium fluoride take the form of 'mild' abrasion and microcracks leading to the detachment of small-sized particles. 
Fig. 15 Low-magnification SEM observation of the worn surfaces: a calcium fluoride surface with local third body in certain areas, b OMC surface
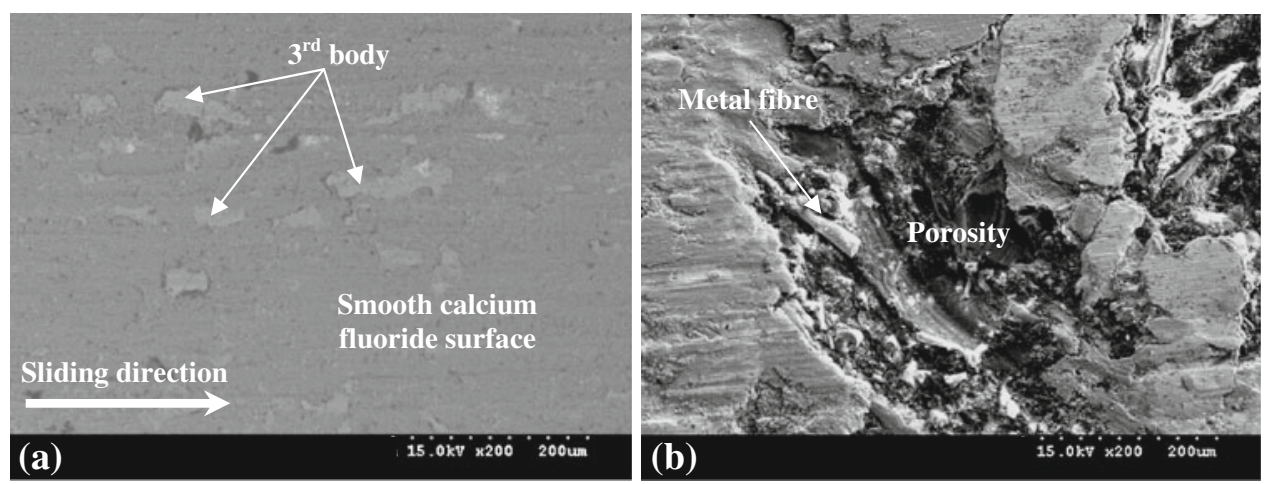



Fig. 16 High-magnification SEM observation of the worn surface of the calcium fluoride. 'Mild' scratches resulting from abrasion mechanisms and propagation of microcracks on the rubbed surface

It has been shown that the introduction of a small calcium fluoride 'window' in the friction pad does not affect the macroscopic friction coefficient of the friction pair. Contrary to preconceived notions, calcium fluoride has high tribological performance, which may be of interest in certain tribological applications. Calcium fluoride was, therefore, found to be a good candidate for use as an infrared-transparent first body for in situ thermal and/or optical observations by IR cameras or pyrometers in sliding contact during friction.

Acknowledgments The present research work has been supported by the International Campus on Safety and Intermodality in Transportation, the Nord-Pas-de-Calais Region, the European Community, the Regional Delegation for Research and Technology, the Ministry of Higher Education and Research, and the National Centre for Scientific Research.

\section{References}

1. Kasem, H., Bonnamy, S., Rousseau, B., Estrade-Szwarckopf, H., Berthier, Y., Jacquemard, P.: Interdependence between wear process, size of detached particles and $\mathrm{CO}_{2}$ production during carbon/carbon composite friction. Wear 263, 1220-1229 (2007)
2. Cristol-Bulthé, A.L., Desplanques, Y., Degallaix, G., Berthier, Y.: Mechanical and chemical investigation of the temperature influence on the tribological mechanisms occurring in $\mathrm{OMC} /$ cast iron friction contact. Wear 264, 815-825 (2008)

3. Bogdanovich, P.N., Tkachuk, D.V.: Temperature distribution over contact area and "hot spots" in rubbing solid contact. Tribol. Int. 39, 1355-1360 (2006)

4. Panier, S., Dufrénoy, P., Weichert, D.: An experimental investigation of hot spots in railway disc brakes. Wear 256, 764-773 (2004)

5. Abdel-Aal, H.A.: On the size of hot spots in the dry sliding of metals. Int. Commun. Heat Mass Transf. 26(3), 441b-450b (1999)

6. Thomas, J., Steven, C., Ball, K.J., Bedell, B.C.: Thermal cracking in disc brakes. Eng. Fail. Anal. 9, 63-76 (2002)

7. Dufrénoy, P., Bodovillé, G., Degallaix, G.: Damage mechanisms and thermomechanical loading of brake discs. Eur. Struct. Integr. Soc. 29, 167-176 (2002)

8. Eleod, A., Oucherif, F., Devecz, J., Berthier, Y.: Conception of numerical and experimental tools for study of the tribological transformation of surface TTS. Tribology (Elsevier Science) 36, 673-682 (1998)

9. Berthier, Y.: Third body reality, consequence and use of the third body to solve a friction and a wear problem. Wear, Materials, Mechanisms and Practice, Gwidon Stachowiack, Wiley Editor ISBN 0-470-1628-0, pp. 291-316 (2005)

10. Yvtushenko, A., Ivanik, E.: Determination of temperatures for sliding contact with application for braking systems. Wear 206, 53-59 (1997)

11. Day, A.J., Newcomb, T.P.: Dissipation of frictional energy from the interface of an annular disc brake. Proc. Inst. Mech. Eng. D Transp. Eng. 198(11), 201-209 (1984)

12. Santini J.J., Kennedy F.E.: Experimental investigation of surface temperatures and wear in disk brakes. Lubr. Eng. 31(8), 402-404, 413-417 (1975)

13. Qi, H.S., Day, A.J.: Investigation of disc/pad interface temperatures in friction braking. Wear 262, 505-513 (2007)

14. Denape, J., Laraqi, N.: Aspect thermique du frottement: mise en évidence expérimentale et éléments de modélisation. Méc. Ind. 1, 563-579 (2000)

15. Kennedy, F., Frusescu, D., Li, J.: Thin film thermocouple arrays for sliding surface temperature measurement. Wear 207, 46-57 (1997)

16. Kasem, H., Bonnamy, S., Berthier, Y., Dufrénoy, P., Jacquemard, P.: Tribological, physicochemical and thermal study of the abrupt friction transition during carbon/carbon composite friction. Wear 267, 846-852 (2009)

17. Siroux, M., Harmand, S., Desmet, B.: Experimental study using infrared thermography on the convective heat transfer of a TGV brake disc in the actual environment. Opt. Eng. 41(7), 1558-1564 (2002) 
18. Kasem, H., Thevenet, J., Boidin, X., Siroux, M., Dufrénoy, P., Desmet, B., Desplanques, Y.: An emissivity-corrected method for the accurate radiometric measurement of transient surface temperatures during braking. Tribol. Int. 43, 1823-1830 (2010)

19. Thevenet, J., Siroux, M., Desmet, B.: Measurements of brake disc surface temperature and emissivity by two-color pyrometery. Appl. Therm. Eng. 30, 753-759 (2010)

20. Bair, S., Green, I., Bhushan, B.: Measurements of asperity temperatures of a read/write head slider bearing in hard magnetic recording disks. Trans. ASME J. Tribol. 113(3), 547-554 (1991)

21. Watremez, M., Drobecq, V., Guérin, J.D., Bricout, J.P.: De la similitude au comportement réel. Application aux disques de freins ferroviaires. Journées CETIM Frottement et usure: Conception et tests des solutions industrielles, France, Senlis, décembre (1999)

22. Bartys, H., Guérin, J.D. Bricout, J.P., Oudin, J.: Caractérisation de disques de freins ferroviaires revêtus de superalliages Co ou Ni. Mec. Ind. 675-682 (2000)

23. Thevenet, J.: Développement d'une métrologie thermique des contacts glissants en freiange. Thèse de doctorat, Université de Valenciennes (2009)

24. Liu, W., Ye, C., Chen, Y., Ou, Z., Sun, D.C.: Tribological behavior of sialon ceramics sliding against steel lubricated by fluorine-containing oils. Tribol. Int. 35, 503-509 (2002) 